\title{
THE RHEOLOGICAL BEHAVIOR OF THE MIXTURES OF CASTOR OIL WITH ADIPIC ESTERS
}

\author{
ANDRA TĂMAŞa ${ }^{\text {, SORINA BORAN }}{ }^{\text {** }}$
}

\begin{abstract}
The paper presents the rheological behavior study of the mixtures of castor oil with two types of adipic esters. The influence of adipic esters' structure and concentration was determined, as well as that of temperature, on the rheological behavior, by setting the dependence between the shear stress $\tau$ and the shear rate $\dot{\gamma}$. The analysis of the dependence between $\tau$ and $\dot{\gamma}$ demonstrates that the studied solutions present Newtonian behavior. The evolution of samples' viscosity with temperature was characterized by Arrhenius type equations, being established the values of viscous flow activation energy, $E_{a}$. It was also realized a characterization of annulus fluids flow under the effect of rotational motion, calculating the values of dimensionless criterion Taylor-Reynolds (TaRe).
\end{abstract}

Keywords: adipic ester, flow activation energy, Newtonian behavior, TaylorReynolds number

\section{INTRODUCTION}

The complex aliphatic-aromatic esters have the characteristics of lubricants with high performing physico-chemical, rheological and tribotechnical properties. Vegetable oils, on the other hand, have the characteristics of biodegradable lubricants with no negative impact on the enviroment but which, however, are not as competitive as the synthetic ester based oils.

Currently, we aim to obtain lubricating products that do not influence the environment but which have superior lubricating properties. With the proper formulation of the base oil and the proper use of additive packs,

a Politehnica University Timisoara, Faculty of Industrial Chemistry and Environmental Engineering, 6 V. Pârvan Bd., RO-300223, Timisoara, Romania

*Corresponding author E-mail: sorina.boran@upt.ro 
biodegradable lubricants may be better than conventional lubricants [1]. For this purpose, mixtures of castor oil with two types of adipic esters were prepared in various proportions, and was studied the rheological behavior, as well as the characterization of flow through ring-shaped spaces [2-4].

The adipic esters with complex structure [5-7], with superior lubricating properties, have been synthesized from an aliphatic-aromatic alcohol in conjunction with various aliphatic alcohols of variable length.

The use of mixtures with castor oil is a studied choice, there being a series of studies demonstrating that castor oil is a compound that can bring significant improvements to the properties of the studied final products [8-11].

\section{RESULTS AND DISCUSSION}

The main physico-chemical properties for $\mathrm{C} 1$ (isodecyl and 2-(pnonyl-fenoxy) ethyl adipate) and C2(isotridecyl and 2-(p-nonyl-fenoxy) ethyl adipate) are presented in Table 1. For castor oil and its mixtures with adipic esters, several properties are selectively presented in Table 2. In addition, the kinematic viscosities of the mixtures at two temperature values, as well as the viscosity index, were determined [12].

Table 1. The properties of adipic esters at $20^{\circ} \mathrm{C}$

\begin{tabular}{|c|c|c|c|c|c|c|}
\hline \multirow[t]{2}{*}{ Ester } & \multirow[t]{2}{*}{ Formula } & \multirow[t]{2}{*}{$\mathrm{Mlg} \mathrm{mol}^{-1}$} & \multirow[t]{2}{*}{$\rho / k g ~ m^{-3}$} & \multirow[t]{2}{*}{$n_{D}$} & \multicolumn{2}{|c|}{ 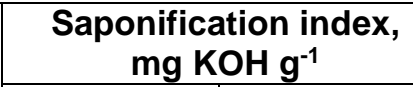 } \\
\hline & & & & & theoretical & analytical \\
\hline C1 & $\mathrm{C}_{33} \mathrm{H}_{56} \mathrm{O}_{5}$ & 532 & 971.5 & 1.4830 & 316.38 & 315.74 \\
\hline $\mathrm{C} 2$ & $\mathrm{C}_{36} \mathrm{H}_{62} \mathrm{O}_{5}$ & 574 & 959.6 & 1.4824 & 293.23 & 293.12 \\
\hline
\end{tabular}

Table 2. Properties of castor oil (CO) and its mixtures with adipic esters at $20^{\circ} \mathrm{C}$

\begin{tabular}{|c|c|c|c|}
\hline Composition, wt.\% & \multicolumn{3}{|c|}{ Property } \\
\hline & $\boldsymbol{\rho} / \mathbf{~ k g ~ m}^{\mathbf{3}}$ & $\boldsymbol{n}_{\boldsymbol{D}}$ & lodine value, $\mathbf{g ~ I}_{\mathbf{2}} / \mathbf{1 0 0} \mathbf{~ g}$ \\
\hline C1/CO & 960.1 & 1.4781 & 86.00 \\
\hline $0 / 100$ & 964.2 & 1.4789 & 39.41 \\
\hline $25 / 75$ & 965.5 & 1.4811 & 22.67 \\
\hline $50 / 50$ & 968.7 & 1.4815 & 15.12 \\
\hline $75 / 25$ & \multicolumn{3}{|}{} \\
\hline C2/CO & 956.0 & 1.4794 & 50.06 \\
\hline $25 / 75$ & 959.8 & 1.4808 & 41.22 \\
\hline $50 / 50$ & 959.6 & 1.4821 & 20.16 \\
\hline $75 / 25$ & \multicolumn{3}{|}{} \\
\hline
\end{tabular}


The influence of the ester type in mixtures with castor oil on their rheological behavior has been studied for different ester concentrations, at 3 temperature values. The dependence $\tau=f(\dot{\gamma})$ for the mixtures with 25 wt.\% adipic esters is shown in Figure 1 and the obtained rheological equations are shown in Table 3.

It is noted that increasing the number of carbon atoms of the aliphatic alcohol used in the esterification leads to a slightly increase of the mixtures viscosity, but not modify their Newtonian behavior. Also, the increase in temperature leads to the decrease of the viscosity of the mixtures without altering their rheological behavior.

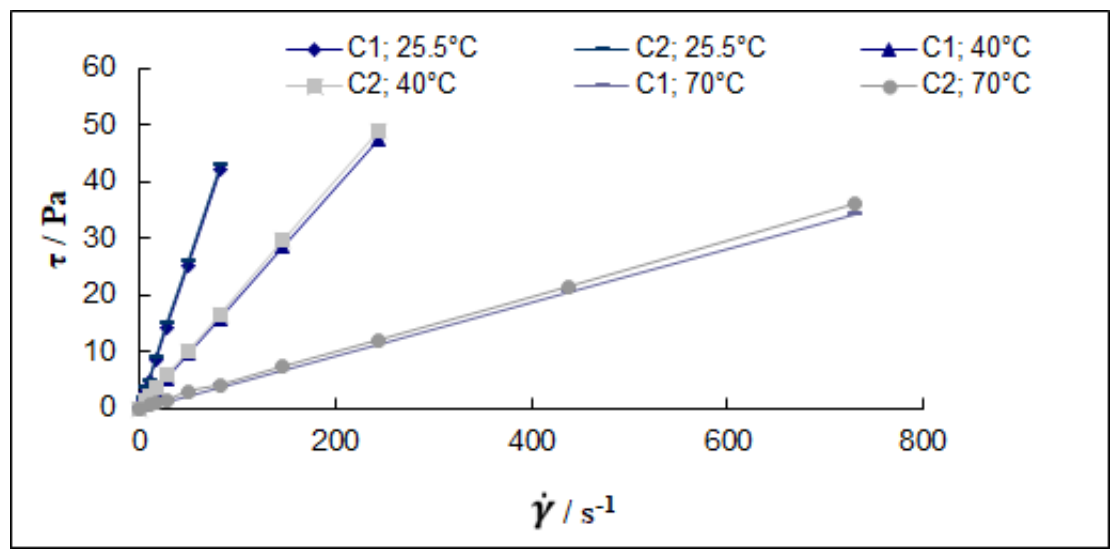

Figure 1. Shear stress vs. shear rate for the mixtures with $25 \mathrm{wt} . \%$ adipic esters

Table 3. Rheological equations of the mixtures with $25 \mathrm{wt} . \%$ adipic esters

\begin{tabular}{|c|c|c|c|}
\hline \multirow{2}{*}{$\begin{array}{c}\text { Temperature, } \\
{ }^{\circ} \mathrm{C}\end{array}$} & \multicolumn{2}{|c|}{ Eq. $\tau=\eta \cdot \dot{\gamma}$} & \multirow{2}{*}{$\begin{array}{c}\text { Viscosity } \\
\text { decreasing }^{*}, \%\end{array}$} \\
\hline & $\mathrm{C} 1+\mathrm{CO}$ & $\mathrm{C2}+\mathrm{CO}$ & \\
\hline 25.5 & $\tau=0.5184 \cdot \dot{\gamma}$ & $\tau=0.5265 \cdot \dot{\gamma}$ & 1.56 \\
\hline 40 & $\tau=0.1941 \cdot \dot{\gamma}$ & $\tau=0.1993 \cdot \dot{\gamma}$ & 2.68 \\
\hline 70 & $\tau=0.0464 \cdot \dot{\gamma}$ & $\tau=0.0471 \cdot \dot{\gamma}$ & 1.51 \\
\hline
\end{tabular}

*Sample with C1 compared with sample with C2

In addition, the influence of the esters' concentration in the mixtures with castor oil was studied. Thus, for the mixtures $\mathrm{C} 2 / \mathrm{CO}$ at $25.5^{\circ} \mathrm{C}$, the dependence $\tau=f(\dot{\gamma})$ is shown in Figure 2 . 


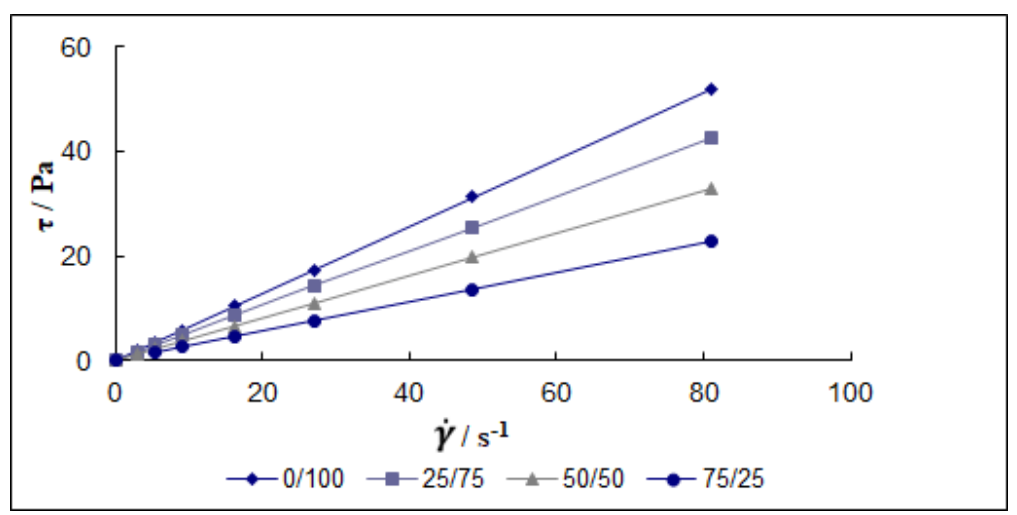

Figure 2. Shear stress vs. shear rate for the mixtures $\mathrm{C} 2 / \mathrm{CO}$ at $25.5^{\circ} \mathrm{C}$

From the slope of the obtained straight lines, it was observed that the mixtures containing adipic ester $\mathrm{C} 2$ have less viscosity compared to the viscosity of castor oil, the decrease being more pronounced with the increase of the ester content and with the increase of temperature. The mixtures $\mathrm{C} 1 / \mathrm{CO}$ presents similar behavior, too. The obtained viscosity values are presented in Table 4.

Table 4. Dynamic viscosities of the samples

\begin{tabular}{|c|c|c|c|c|c|c|c|}
\hline \multirow{2}{*}{$\begin{array}{l}\text { wt.\% } \\
\text { C1 }\end{array}$} & \multicolumn{2}{|c|}{ n/mPa.s } & \multirow{2}{*}{$\begin{array}{c}\text { Viscosity } \\
\text { decreasing } \%\end{array}$} & \multirow{2}{*}{\begin{tabular}{|c|} 
wt. \% \\
C2
\end{tabular}} & \multicolumn{2}{|c|}{ n/mPa.s } & \multirow{2}{*}{$\begin{array}{c}\text { Viscosity } \\
\text { decreasing*\% }\end{array}$} \\
\hline & $25.5^{\circ} \mathrm{C}$ & $70^{\circ} \mathrm{C}$ & & & $25.5^{\circ} \mathrm{C}$ & $70^{\circ} \mathrm{C}$ & \\
\hline 0 & 643.7 & 66.8 & - & 0 & 643.7 & 66.8 & 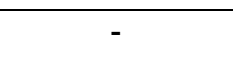 \\
\hline 25 & 518.4 & 46.4 & $19.5 / 30.5$ & 25 & 526.5 & 47.1 & $18.2 / 29.5$ \\
\hline 50 & 392.3 & 29.0 & $39.1 / 56.6$ & 50 & 404.5 & 30.4 & $37.2 / 54.5$ \\
\hline 75 & 271.1 & 15.6 & $57.9 / 76.6$ & 75 & 281.5 & 16.5 & $56.3 / 75.3$ \\
\hline
\end{tabular}

* compared to castor oil, at $25.5^{\circ} \mathrm{C}$ and $70^{\circ} \mathrm{C}$, respectively

The exponential decrease of the mixtures' viscosity with temperature is described by an Arrhenius-type equation:

$$
\eta=A \cdot \exp \left(\frac{E_{a}}{R \cdot T}\right)
$$


where $E_{a}$ is the activation energy of the viscous flow, $\mathrm{J} \mathrm{mol}^{-1}, R$ the universal gas constant, $\mathrm{J} \mathrm{mol}^{-1} \mathrm{~K}^{-1}, T$ absolute temperature and $A$ is a material constant, Pa s.

Through the measurements at different temperatures, it was possible to establish the dependence $\ln \eta=f(1 / T)$ and to calculate the $E_{a}$ values. Particular expressions of equation (1) for adipic esters/castor oil mixtures are presented in Table 5.

Table 5. Arrhenius-type equations for the analyzed mixtures

\begin{tabular}{|c|c|c|}
\hline $\begin{array}{c}\text { Ester content, } \\
\text { wt.\% }\end{array}$ & Eq. $\eta=A \times 10^{9} \cdot \exp \left(E_{a} / R \cdot T\right)$ & $E_{a} / \mathbf{~ k J ~ m o l}^{-1}$ \\
\hline 0 & $\eta=17.1 \cdot \exp (5207 / T)$ & 43.3 \\
\hline $25(\mathrm{C} 1)$ & $\eta=5.6 \cdot \exp (5463 / T)$ & 45.4 \\
\hline $25(\mathrm{C} 2)$ & $\eta=5.0 \cdot \exp (5499 / T)$ & 45.7 \\
\hline $50(\mathrm{C} 1)$ & $\eta=1.0 \cdot \exp (5872 / T)$ & 48.8 \\
\hline $50(\mathrm{C} 2)$ & $\eta=1.2 \cdot \exp (5836 / T)$ & 48.5 \\
\hline $75(\mathrm{C} 1)$ & $\eta=0.13 \cdot \exp (6354 / T)$ & 52.8 \\
\hline $75(\mathrm{C} 2)$ & $\eta=0.14 \cdot \exp (6342 / T)$ & 52.7 \\
\hline
\end{tabular}

It is found that at the same concentration of the ester, the values of the flow activation energy are very close and increase with increasing the ester content.

Since lubrication is usually used in rotating systems (bearings, gears etc), the dynamic characteristics (speed, dynamic pressure, shear stress) will be expressed in terms of Taylor-Reynolds number $\left(T a_{R e}\right)$ specific to this type of motion. This criterion is also used to characterize fluids flow in ringshaped spaces (the space bounded by the two coaxial cylinders) under the effect of a controlled rotational motion (the revolution of the inner cylinder).

The values of $T a_{R e}$ number were calculated using relation (2), taking into account the radii of the inner and outer cylinder $\left(r_{i}\right.$ and $\left.r_{0}\right)$, the inner cylinder revolution number, $n$, and the fluid properties (viscosity $\eta$ and density $\rho)[4,13]$ :

$$
T a_{\mathrm{Re}}=\frac{2 \cdot \pi \cdot n \cdot r_{i} \cdot\left(r_{o}-r_{i}\right) \cdot \rho}{\eta}
$$

Increasing the hydrodynamic regime leads to a pronounced decrease of the ratio between shear stress $\tau$ (experimentally determined) and dynamic 
pressure $P_{d y n}$. This ratio is a direct measure of the increase in centrifugal or inertial forces, in correlation with the viscous friction force, depending on the $T a_{R e}$ number. By analogy with fluids flow through straight pipes, the dynamic pressure of the fluid in motion in ring-shaped spaces is calculated by:

$$
\begin{aligned}
& P_{d y n}=\frac{\rho \cdot w_{\max }^{2}}{2} \\
& w_{\max }=\pi \cdot d_{i} \cdot n
\end{aligned}
$$

where $w_{\max }$ is the speed of the fluid laminar layer placed next to the moving wall (inner cylinder) and $d_{i}$ is the inner diameter of the ring-shaped space.

For the analyzed samples, at a constant temperature $\left(40^{\circ} \mathrm{C}\right)$, the dependence $\tau / P_{d i n}=f\left(T a_{\mathrm{Re}}\right)$ is shown in Figure 3 .

It can be seen that the graphical representation places the results after a parabolic curve, without significant changes depending on the ester type or concentration. Also, it is noted an accentuated decrease in the ratio $\tau / P_{d y n}$ with the increase of hydrodynamic flow regime and the increase of ester concentration.

By analogy with the circular motion of the fluid in stirring processes $[2-4,14]$, the ratio $\tau / P_{d y n}$ is correlated with $T a_{R e}$ number by a relatioship of type:

or, in the linear logarithmic form:

$$
\tau / P_{d y n}=C \cdot T a_{\mathrm{Re}}^{m}
$$

$$
\ln \left(\tau / P_{d y n}\right)=\ln C+m \cdot \ln \left(T a_{\mathrm{Re}}\right)
$$

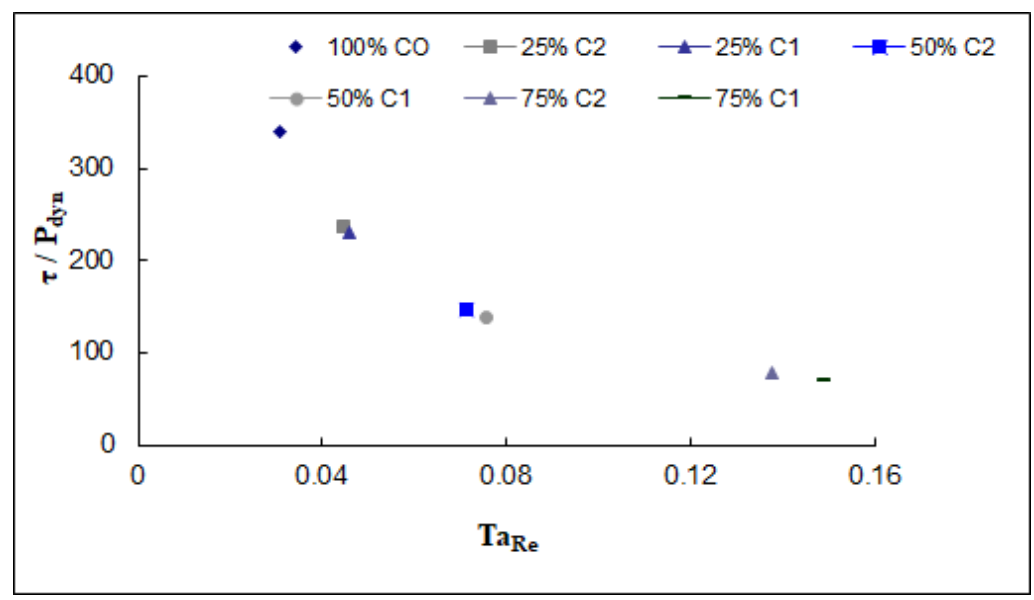

Figure 3. Ratio $\tau / P_{d i n} v s . T a_{\mathrm{Re}}$ for the mixtures adipic ester/castor oil at $40^{\circ} \mathrm{C}$ 
The particular forms of relation (5b), determined for the mixtures $\mathrm{C} 1 / \mathrm{CO}$, at $40^{\circ} \mathrm{C}$, are shown in Table $6 \mathrm{a}$, and for the samples with $25 \mathrm{wt} . \%$ adipic esters, at different temperature values, are shown in Table $6 \mathrm{~b}$.

Table 6a. Particular forms of eq. (5b) for the mixtures $\mathrm{C} 1 / \mathrm{CO}$ at $40^{\circ} \mathrm{C}$

\begin{tabular}{|c|c|c|}
\hline Ester content, wt.\% & Eq. $\ln \left(\tau / P_{\text {din }}\right)=\ln C+m \cdot \ln \left(T a_{\mathrm{Re}}\right)$ & $\mathbf{C}$ \\
\hline 0 & $\ln \left(\tau / P_{\text {din }}\right)=2.3515-1.0008 \cdot \ln \left(T a_{\mathrm{Re}}\right)$ & 10.5 \\
\hline 25 & $\ln \left(\tau / P_{\text {din }}\right)=2.3530-1.0004 \cdot \ln \left(T a_{\mathrm{Re}}\right)$ & 10.517 \\
\hline 50 & $\ln \left(\tau / P_{\text {din }}\right)=2.3536-1.0002 \cdot \ln \left(T a_{\mathrm{Re}}\right)$ & 10.523 \\
\hline 75 & $\ln \left(\tau / P_{\text {din }}\right)=2.3539-\ln \left(T a_{\mathrm{Re}}\right)$ & 10.526 \\
\hline
\end{tabular}

Table 6b. Particular forms of eq. (5b) for the mixtures adipic ester/CO 25/75 wt.\%

\begin{tabular}{|c|c|c|}
\hline Temperature, $^{\circ} \mathrm{C}$ & Eq. $\ln \left(\tau / P_{d i n}\right)=\ln C+m \cdot \ln \left(T a_{\mathrm{Re}}\right)$ & $\mathbf{C}$ \\
\hline \multicolumn{3}{|c|}{ C1 } \\
\hline 25.5 & $\ln \left(\tau / P_{d i n}\right)=2.5173-0.9643 \cdot \ln \left(T a_{\mathrm{Re}}\right)$ & 12.395 \\
\hline 40 & $\ln \left(\tau / P_{d i n}\right)=2.3530-1.0004 \cdot \ln \left(T a_{\mathrm{Re}}\right)$ & 10.517 \\
\hline 70 & $\ln \left(\tau / P_{\text {din }}\right)=2.3443-1.0035 \cdot \ln \left(T a_{\mathrm{Re}}\right)$ & 10.426 \\
\hline \multicolumn{3}{|c|}{ C2 } \\
\hline 25.5 & $\ln \left(\tau / P_{d i n}\right)=2.3540-\ln \left(T a_{\mathrm{Re}}\right)$ & 10.527 \\
\hline 40 & $\ln \left(\tau / P_{\text {din }}\right)=2.3530-1.006 \cdot \ln \left(T a_{\mathrm{Re}}\right)$ & 10.517 \\
\hline 70 & $\ln \left(\tau / P_{d i n}\right)=2.3538-1.0005 \cdot \ln \left(T a_{\mathrm{Re}}\right)$ & 10.525 \\
\hline
\end{tabular}

The values of parameter $C$ in relation (5a) can be considered as an equilibrium value of Taylor-Reynolds number $\left(T a_{\mathrm{Re}}^{*}\right)$, taking into account the condition of equality between shear stress and dynamic pressure $\left(\tau / P_{d y n}=1\right.$ or $\left.\ln \left(\tau / P_{d y n}\right)=0\right)$. For all the analyzed samples, the equilibrium values are less than the critical value $\left(T a_{\mathrm{Re}, c r}=60\right)$ specific to laminar flow of the fluids in ring-shaped spaces $[13,15]$.

Under these conditions, assuming that the shear stress $\tau$ is equivalent to the friction pressure drop, it can be accept that the ratio of the two parameters is equal to the friction coefficient $\lambda$ corresponding to laminar 
flow regime $\left(\lambda=64 \cdot \mathrm{Re}^{-1}\right)$. On the other hand, from the equations presented in Tables $6 \mathrm{a}$ and $6 \mathrm{~b}$, it can be noticed that the values of $m$ are very close to -1 , similar to the exponent of Reynolds number in the friction coefficient expression, and that the values of $C$ slightly increase with increasing the ester concentration.

\section{CONCLUSIONS}

It was studied the rheological behavior of the mixtures of castor oil with two types of adipic esters, monitoring the influence of the temperature, as well as that of the ester type and concentration. Also, the behavior of these mixtures at the flow through ring-shaped spaces was analyzed.

For each analyzed sample it was obtained a linear dependence between shear stress $\tau$ and shear rate $\dot{\gamma}$, without yield point $\tau_{0}$, which shows that castor oil and its mixtures with adipic esters presents Newtonian behavior, regardless of the temperature and type and concentration of the ester, respectively. The addition of adipic esters in castor oil leads to viscosity decreasing, the decrease being proportional to the increase in ester concentration.

From the Arrhenius type equations it is noted that the values of the viscous flow activation energy increase with the increase of the ester concentration in the mixture, but, under the same conditions, the values of the pre-exponential coefficient decrease. At the same concentration of the ester, the values of the two parameters $\left(E_{a}, A\right)$ are very close, not being influenced by the modify in the number of carbon atoms of the aliphatic alcohol used in the esterification.

For the analyzed mixtures, the dependence between the rheological parameters and the Taylor-Reynolds number, was established. From the graphical representations of this dependence it can be concluded that, through the ring-shaped space (delimited by the two coaxial cylinders) of the Rheotest-2 viscometer, the flow of the mixtures of castor oil with adipic esters takes place in the laminar regime.

\section{EXPERIMENTAL SECTION}

General procedure for ester preparation

The preparation of the adipic esters was performed according to our previously reported procedure [5-7] by reacting the adipic acid with 2-(p- 
Nonylphenoxy)ethanol in conjunction with an aliphatic alcohol of 10 or 13 carbon atoms, by a two steps process, using $p$-toluenesulphonic acid as catalyst. The formed water was extracted azeotropically by means of toluene. These two esters are illustrated in the following general structure $\mathrm{R}_{1} \mathrm{OOC}-\left(\mathrm{CH}_{2}\right)_{4}-\mathrm{COOR}_{2}$, where: $\mathrm{R}_{1}=$ isodecyl or isotridecyl; $\mathrm{R}_{2}=-\mathrm{CH}_{2}-\mathrm{CH}_{2}-$ $\mathrm{O}-\mathrm{C}_{6} \mathrm{H}_{4}-\mathrm{R}_{3} ; \mathrm{R}_{3}=p$-nonyl.

The castor oil was supplied by Fluka. The samples preparation was realized at room temperature $\left(25^{\circ} \mathrm{C}\right)$, under intense stirring.

The physico-chemical properties were determined by using standardized techniques: the pycnometer method for density determination and the Abbe refractometer for refractive indices.

The rheological measurements were carried out under thermostatic conditions, at different temperatures ranging from $25.5^{\circ} \mathrm{C}$ to $70^{\circ} \mathrm{C}$, using a Rheotest-2 rotational viscometer with the system vat-drum $S / S_{1}$. The device allows the measurement of the torsion moment appeared thanks to the ring-shaped substance layer placed between a fixed cylinder and a rotating one with known revolution. The torsion moment is correlated with the shear stress. The revolution and the ring-shaped layer thickness determine the shear rate. Shear rate values were changed in the range $3 \div 729 \mathrm{~s}^{-1}$.

\section{REFERENCES}

1. A.Z.Syahir, N.W.M. Zulkifli, H.H. Masjuki, M.A. Kalam et.al., Journal of Cleaner Production, 2017, 168, 997.

2. S. Boran, A. Tămaș, Studia UBB Chemia, 2013, LVIII, 3, 21

3. S. Boran, A. Tămaș, Journal of the Serbian Chemical Society, 2014, 79(2), 241.

4. Z. Gropșian, A. Tămaș, R. Minea, N. Borș, Bulletin of Romanian Chemical Engineering Society, 2014, 1(1), 91.

5. L. Mirci, S. Boran, Materiale Plastice, 2007, 44(4), 383.

6. L. Mirci, S. Boran, P. Luca, V. Boiangiu, $15^{\text {th }}$ International Colloquium Tribology- Technische Akademie Esslingen, Ostfildern, Germania, 17-19 Jan. 2006, Synopses Synthetic Oils, 236.

7. L. Mirci, S. Boran, RO 122.453, 2009.

8. L. Xia, D. Cao, H. Zhang, Y. Guo, Construction and Building Materials, 2016, $112,949$.

9. G. Totaro, L. Cruciani et.al., European Polymer Journal, 2014, 56, 174.

10. R.M.A. Saboya, J.A. Cecilia, C. Garcia-Sancho, A.V. Sales et.al., Industrial Crops and Products, 2017, 104, 52. 
11. M. Ozcanli, M. Atakan Akar, A. Calik, H. Serin, International Journal of Hydrogen Energy, 2017, 42, 23366.

12. S. Boran, A. Tămaș, Materiale Plastice, 2016, 53(3), 505.

13. N. Borss, "Contributions to the study of the influence of some chemical substances on improving flow", PhD Thesis, Ed. Politehnica, Timișoara, 2010, 80.

14. A. Tămaș, N. Borș, R. Minea, Petroleum-Gas University of Ploiești Bulletin, Technical Series, 2008, LX, 105.

15. D.E. McMillan, J. Strigberger, N.G. Utterback, Biorheology, 1987, 24(4), 401. 